\title{
Inappropriate medicine prescribing in older South Africans: A cross-sectional analysis of medicine claims data
}

\author{
J A van Heerden, BPharm; J R Burger, BPharm, MPharm, PhD (Pharm Pract); J J Gerber, BSc (Pharm) Hons, BSc (Ind Pharm), \\ MSc (Ind Pharm) Hons, BSc (Pharmacol), DSc (Pharm)
}

Medicine Usage in South Africa (MUSA), Faculty of Health Sciences, North-West University (Potchefstroom campus), South Africa

Corresponding author: J Burger (johanita.burger@nwu.ac.za)

\begin{abstract}
Background. Prescribing for older patients is a well-recognised problem, and inappropriate items are prescribed frequently. Several tools and criteria are available to promote rational prescribing in older patients.

Objective. To determine the prevalence of potentially inappropriate prescriptions (PIPs) in older South African patients.

Methods. A retrospective drug utilisation review was conducted using medicine claims data over a 1 -year period. Patients aged $\geq 65$ years with at least one paid claim for any medicine item during this period were included. The prevalence of PIPs was identified by applying the 2012-Beers criteria list. Results. A total of 103420 patients, mean age 74.0 years (standard deviation 6.7), 57.1\% female, were included in the analysis. The number of PIPs identified was 562852 in 71206 patients (68.9\%). The most common medicines inappropriately prescribed were oestrogen (oral and patch formulations only) (12.4\%), meloxicam (7.3\%), amitriptyline and combinations thereof (6.5\%), diclofenac (6.4\%), ibuprofen (6.1\%), alprazolam (5.3\%), meprobamate and combinations thereof (5.0\%), sliding-scale insulin (3.3\%), amiodarone (3.1\%) and doxazosin (2.6\%). Medicines were inappropriately prescribed to women statistically significantly more often than to men $(1.9: 1 ; p<0.001)$, although this difference was not of practical significance (Cramér's $V=0.06$ ).

Conclusions. Medicine use in older patients must be appropriate and evaluated regularly. According to explicit criteria, PIPs were found to be common in older patients registered on the database. Monitoring of PIPs may increase the quality of prescribing, but explicit criteria cannot substitute for clinical judgement based on the individual patient.
\end{abstract}

S Afr Med J 2016;106(10):1010-1016. DOI:10.7196/SAMJ.2016.v106i10.10627

Altered pharmacokinetics and pharmacodynamics associated with ageing may contribute to drugs being classified as inappropriate for use in older adults. ${ }^{[1]}$ With the number of older and very old people increasing rapidly, ${ }^{[2]}$ inappropriate medicine prescribing in the older population is becoming a well-recognised problem. ${ }^{[3]}$ Developing countries such as South Africa (SA) are not exempt from the effects of an ageing population. For instance, the pensioner ratio in SA increased from $5.9 \%$ in 2001 to $7.3 \%$ in $2014,{ }^{[4]}$ with approximately half of older patients in the private health sector of SA suffering from more than one chronic disease, some being diagnosed with up to 11 conditions. ${ }^{[5]}$ There has been an increase in the complexity of medication regimens used to treat older patients, and they usually have multiple prescribers. Careful planning and knowledge of the ageing process and the drugs prescribed are essential in prescribing for older patients, as they are at an increased risk of developing drugrelated problems. ${ }^{[6]}$

Several tools and criteria to improve rational medicine use in older patients are available. These can be grouped into implicit and explicit tools, and tools based on a combination of these two. The Beers criteria list is one of the most frequently applied and adopted explicit screening tools to assess potentially inappropriate prescriptions (PIPs). It has been adopted by numerous medical aid groups and administrators to pinpoint older patients with an increased probability of experiencing negative outcomes related to PIP, and it has shown to be a useful tool for assessing PIP in large populations. ${ }^{[1]}$

A review of US-based studies ${ }^{[7]}$ indicated that almost $40 \%$ of people living in care facilities for the aged received inappropriate prescriptions, and almost half as much was seen in communitydwelling people aged $\geq 65$ years. A similar Australian-based study ${ }^{[8]}$ found that almost $20 \%$ of patients aged $\geq 70$ years had at least one inappropriate prescription during a 6 -month period. Similar to these, an earlier study conducted in SA to identify potentially inappropriate medicine items prescribed to older patients showed that $30 \%$ of prescriptions ( $n=6410)$ included at least one potentially inappropriate item. ${ }^{[9]}$ A common finding is that older female patients are more likely than older males to be prescribed potentially inappropriate medication. ${ }^{[9]}$ Some of the most common potentially inappropriate medicine items prescribed are those acting on the cardiovascular system, psychotropic agents and neuroleptic agents, especially those for neuropathic pain. Specific medicine items include amitriptyline, benzodiazepines, doxazosin, proton-pump inhibitors, non-steroidal anti-inflammatory agents (NSAIDs), digoxin, antihistamines and oestrogen (only oral and patch formulations).

\section{Objective}

Our study focused only on the private health sector of SA, which comprises approximately $16 \%$ of the country's total health sector. In December 2014, the total number of medical aid beneficiaries was 8.81 million, which consisted of more female (52.5\%) than male (47.5\%) beneficiaries. ${ }^{[4]}$ Although the private sector serves almost a quarter of the SA population, data on the utilisation of medicine items in the private sector are difficult to access as most of the medical aid administrators regard such data as proprietary. The general objective of the study was to investigate medicine prescribing patterns for older patients in the private health sector of SA utilising the 2012-Beers criteria list ${ }^{[10]}$ for PIPs.

\section{Method \\ Design and data source}

A cross-sectional analysis was conducted using a database obtained from a well-known SA pharmaceutical benefit management company (PBM). At the time, the PBM used had approximately 22 years of 
service excellence and more than 1.6 million South Africans were benefiting from its services. The company provided services to 35 medical aid schemes and five capitation provider clients administered by 15 different healthcare administrators. ${ }^{[4]}$ At the time of writing, the PBM was linked up to all SA's pharmacies and $98 \%$ of all dispensing doctors.

The database for the period 1 January - 31 December 2013 contained pharmaceutical claims information for a total of 8776279 patients. A total of 103420 patients on the database were aged $\geq 65$ years (44343 men, 59077 women), representing $2.5 \%$ of all people aged $\geq 60$ years with medical aid coverage across SA during 2013. ${ }^{[1]} \mathrm{We}$ queried data fields for patient demographic information (sex and date of birth), and pertinent prescription information (drug trade name, strength, how many days' supply, quantity and treatment date). Date of birth and treatment date were used to calculate the age of patients on the day of treatment.

\section{Assessment of PIP}

The 2012-Beers criteria list ${ }^{[10]}$ was used to identify PIPs of medicine items among older patients by counting the number of drugs on the Beers criteria list per prescription. Some drugs listed in the 2012-Beers criteria are marketed under different names in SA. For example, mepiridine is known as pethidine, scopolamine as hyoscine and phenobarbital as phenobarbitone. Any item listed in the 2012-Beers criteria that was not available in SA at the time of the study was excluded.

\section{Statistical analysis}

Variables were characterised using 95\% confidence intervals (CIs), descriptive statistics such as proportions/ratios for categorical variables, and means and standard deviations (SDs) for continuous variables. An independent two-sample $t$-test (assuming unequal variances) was used to assess the statistical significance of the age difference between men and women. The $\chi^{2}$ test was performed to determine the association between the prevalence of the Beers criteria list items and gender or age group. Because statistical significance tests yielded small $p$-values (indicating significance), in most tests we focused our interpretation on effect sizes, which are independent of units and sample size. Cohen's $d$-value was used to evaluate mean differences between groups (with significance defined as a level of at least 0.8 ), and Cramér's $V$ statistic (defined as a level of at least 0.5 ) was used for associations between categorical variables. Statistical analyses were performed using SAS software, version 9.3 (SAS, USA).

\section{Results}

\section{Study population characteristics}

A total of 103420 patients aged $\geq 65$ years (male/female ratio 1:1.3) were included in the study. Their characteristics are shown in Table 1. There was no difference in the mean age of female and male patients $(p<0.001$; Cohen's $d=0.10)$.

A total of 1544268 prescriptions were claimed for older patients, at an average of 14.9 (SD 9.5) per patient (95\% CI 14.87 14.99). Women received more prescriptions than men $(58.6 \%$ v. $41.0 \%)$, but there was no difference between the sexes in terms of the average number of prescriptions claimed per patient $(p<0.001$; Cohen's $d=0.09$ ). A total number of 4231014 drugs were prescribed, of which 2494560 (59.0\%) were prescribed to women. A mean of 2.7 drugs (SD 2.1) (95\% CI 2.73 - 2.74) were claimed per prescription (median two drugs), with no difference in the average number of drugs per prescription between the sexes $(p<0.001$; Cohen's $d=0.02$ ).

\section{Potentially inappropriate prescribing as determined by the 2012-Beers criteria}

A total of 102 of the 1432012 -Beers criteria items $(71.3 \%)$ were available in SA at the time of the study and therefore utilised to identify PIPs. Application of these criteria to the claims data identified 562852 potentially inappropriate medicine items (13.0\%) prescribed to a total of 71206 patients $(68.9 \%)$. The majority of these patients $(37.2 \%)$ received one potentially inappropriate item, $26.1 \%$ received two and $16.2 \%$ received three. A further $10.7 \%$
( $n=7$ 646) received five or more potentially inappropriate items.

As shown in Table 2, significantly more women $(72.3 \%)$ received potentially inappropriate drugs than men $(64.3 \%)(p<0.001)$. However, this difference in prevalence was not practically significant (Cramér's $V=0.06$ ). There was also no difference between the sexes in terms of the average number of potentially inappropriate items prescribed per patient $(p<0.001$; Cohen's $d=0.16)$. PIPs decreased overall with an increase in age. However, the differences between the age groups in terms of the prevalence of prescribing of inappropriate medicine items were also not practically significant $(p<0.001$; Cramér's $V=0.04$ ).

The most frequently potentially inappropriately prescribed item was oestrogen (oral and patch formulations) (Table 3 ), prescribed in 69894 of the patients $(12.4 \%)$, followed by meloxicam ( $n=41030,7.3 \%)$, amitriptyline and combinations thereof $(n=36509$, $6.5 \%)$, diclofenac $(n=36062,6.4 \%)$, ibuprofen $(n=34162,6.1 \%)$, alprazolam $(n=29896$, $5.3 \%)$, meprobamate and combinations thereof $(n=27894,5.0 \%)$, sliding-scale insulin ( $n=18715,3.3 \%)$, amiodarone ( $n=17433$, $3.1 \%)$ and doxazosin $(n=14816,2.6 \%)$. The $\chi^{2}$ analysis showed that for oestrogen (oral and patch formulations), women received significantly more prescriptions than men $(p<0.001)$; this association was moderate (Cramér's $V=0.27$ ). It also indicated that for both sliding-scale insulin $(p<0.001$; Cramér's $V=0.11)$ and doxazosin $(p<0.001$; Cramér's $V=0.13)$ men received significantly more prescriptions than women. The association for both of these items were small. For the

Table 1. Patient characteristics

\begin{tabular}{llll}
\hline Demographics & $\begin{array}{l}\text { Total study } \\
\text { population }\end{array}$ & Female & Male \\
\hline Patients, $N(\%)$ & 103420 & $59077(57.1)$ & $44343(42.9)$ \\
Age (yr), mean (SD) (95\% CI) & $74.0(6.7)$ & $74.3(6.9)$ & $73.6(6.5)$ \\
& $(73.9-74.0)$ & $(74.2-74.3)$ & $(73.5-73.6)$ \\
Age group (yr), $n(\%)$ & & & \\
$\quad 65 \geq$ age $\leq 68$ & $23027(22.3)$ & $12615(12.2)$ & $10412(10.1)$ \\
$\quad 68<$ age $\leq 72$ & $25066(24.2)$ & $13981(13.5)$ & $11085(10.7)$ \\
$72<$ age $\leq 78$ & $28604(27.7)$ & $16277(15.7)$ & $12327(11.9)$ \\
$\quad$ Age $>78$ & $26723(25.8)$ & $16204(15.7)$ & $10519(10.2)$ \\
Prescriptions, $n(\%)$ & 1544268 & $905582(58.6)$ & $638686(41.4)$ \\
$\begin{array}{l}\text { Prescriptions per patient, mean (SD) } \\
\text { (95\% CI) }\end{array}$ & $14.9(9.5)$ & $15.3(9.6)$ & $14.4(9.4)$ \\
Drugs prescribed, $n(\%)$ & $(14.87-14.99)$ & $(15.25-15.41)$ & $(14.32-14.49)$ \\
$\begin{array}{l}\text { Drugs per prescription, mean (SD) } \\
\text { (95\% CI) }\end{array}$ & 4231014 & $2494560(59.0)$ & $1736454(41.0)$ \\
& $2.74(2.07)$ & $2.76(2.08)$ & $2.72(2.05)$ \\
& $(2.73-2.74)$ & $(2.75-2.76)$ & $(2.71-2.72)$
\end{tabular}


Table 2. Prevalence of potentially inappropriate drugs prescribed for the study population

\begin{tabular}{|c|c|c|c|c|c|}
\hline & $\begin{array}{l}\text { Total study } \\
\text { population }\end{array}$ & Female & Male & $p$-value & Effect size \\
\hline Total potentially inappropriate drugs, $n(\%)$ & 562852 & $371958(66.1)$ & $190894(33.9)$ & $<0.001$ & $0.06^{*}$ \\
\hline \multicolumn{6}{|c|}{ Number of potentially inappropriate drugs per patient, mean (SD) $(95 \% \mathrm{CI})$} \\
\hline Gender & $\begin{array}{l}2.41(1.62) \\
(2.40-2.43)\end{array}$ & $\begin{array}{l}2.52(1.69) \\
(2.51-2.54)\end{array}$ & $\begin{array}{l}2.25(1.52) \\
(2.23-2.27)\end{array}$ & $<0.001$ & $0.16^{\dagger}$ \\
\hline Age group (yr) & & & & $<0.001$ & \\
\hline $65 \geq$ age $\leq 68(n=16124)$ & $\begin{array}{l}2.52(1.74) \\
(2.50-2.55)\end{array}$ & $\begin{array}{l}2.64(1.80) \\
(2.61-2.68)\end{array}$ & $\begin{array}{l}2.36(1.63) \\
(2.32-2.40)\end{array}$ & & $0.16^{\dagger}$ \\
\hline $68<$ age $\leq 72(n=17290)$ & $\begin{array}{l}2.45(1.65) \\
(2.42-2.47)\end{array}$ & $\begin{array}{l}2.57(1.72) \\
(2.54-2.61)\end{array}$ & $\begin{array}{l}2.26(1.52) \\
(2.23-2.30)\end{array}$ & & $0.18^{\dagger}$ \\
\hline $72<$ age $\leq 78(n=19526)$ & $\begin{array}{l}2.41(1.61) \\
(2.38-2.43)\end{array}$ & $\begin{array}{l}2.53(1.68) \\
(2.50-2.57)\end{array}$ & $\begin{array}{l}2.21(1.47) \\
(2.18-2.25)\end{array}$ & & $0.19^{\dagger}$ \\
\hline Age $>78(n=18266)$ & $\begin{array}{l}2.29(1.51) \\
(2.26-2.31)\end{array}$ & $\begin{array}{l}2.36(1.55) \\
(2.34-2.39)\end{array}$ & $\begin{array}{l}2.15(1.43) \\
(2.12-2.19)\end{array}$ & & $0.14^{\dagger}$ \\
\hline $\begin{array}{l}{ }^{*} \text { Cramér's } V \text { statistic. } \\
\text { 'Cohen's } d \text {-value. }\end{array}$ & & & & & \\
\hline
\end{tabular}

other items forming part of the top 10 most frequently prescribed items (i.e. meloxicam, amitriptyline, diclofenac, ibuprofen, alprazolam, meprobamate and amiodarone), there was no significant difference between the sexes (Table 3 ).

General practitioners prescribed the largest number of inappropriate medicine items to the older population (70.7\%), followed by the specialist group (15.7\%), pharmacists (9.0\%) and 'other', which included psychiatrists, radiologists, oncologists and surgeons (4.7\%). Table 4 sets out the 10 most frequently inappropriately prescribed items according to each of these groups. The number of potentially inappropriately prescribed items per prescriber group differed significantly $(p<0.001)$. This association, however, was weak (Cramér's $V=0.09$ ). Of the 102 items listed in the 2012-Beers criteria that were available in SA at the time of the study, a total of 84 were prescribed and identified in the study. Of these 84 items, 71 were prescribed most frequently by general practitioners, followed by pharmacists with 7 items, specialists with 3 items and psychiatric professionals with 3 items (under prescriber group 'other').

\section{Discussion}

Older patients often have multiple diseases requiring multiple drugs. ${ }^{[3]}$ Polypharmacy increases the potential for the prescribing of potentially inappropriate medications ${ }^{[3]}$ The prevalence of PIPs in our study (13.0\%) was found to be lower than that in international studies (ranging from $20 \%$ to $40 \%)^{[7,8]}$ and that found by Chetty and Gray ${ }^{[9]}$ in SA public sector primary healthcare facilities and old-age homes in 2004. However, similar to our study, the screening tool used by Chetty and Gray was adjusted based on the availability of data collected and the list of drugs obtainable in SA. In our study, only 102 of the 143 2012-Beers criteria items were available in SA at the time of the study. These results underscore the importance of adapting the Beers criteria list or developing a country-specific list to fit the needs of a prescribing measure in older adults in the SA health sector.

The rate of inappropriate prescribing is generally higher in women than in men, ${ }^{[9]}$ in accordance with a higher prescription claim rate per female patient. Similarly, in our study women tended to receive more inappropriate medicine items than men; however, we found no difference between the sexes in terms of the average number of prescriptions per patient or the average number of items prescribed per patient, which could have influenced this association. Further studies are therefore needed in the SA private health sector to clarify the dynamics of sex differences in interactions between healthcare providers and patients resulting in women being prescribed more medication.

Studies assessing inappropriate prescribing report that the most common potentially inappropriate medicine items include amitriptyline, benzodiazepines, doxazosin, proton-pump inhibitors, NSAIDs, digoxin, antihistamines and oestrogen. In agreement with these studies, the most frequent potentially inappropriate medicine items prescribed for our population included oestrogen (oral and patch formulations), followed by non-steroidal antiinflammatory drugs, meprobamate and/or combinations thereof, amitriptyline and/or combinations, alprazolam, sliding-scale insulin, amiodarone and doxazosin. The prescribing of oestrogen (oral and patch formulations) among patients in our population was significantly higher in women than in men, whereas for both sliding-scale insulin and doxazosin, men received significantly more prescriptions than women. Oestrogen is essentially used as hormone replacement therapy (HRT) in women with oestrogen deficiency and to ameliorate hot flushes and atrophic changes in the urogenital tract. It is also indicated for preventing bone loss and the development of osteoporosis, and may reduce the risk of coronary artery disease, memory loss and Alzheimer's disease. ${ }^{[12]}$ In men, oestrogen is used for the treatment of low oestradiol (E2) levels from congenital aromatase deficiency. E2 can furthermore be used to relieve hot flushes in men treated with luteinising hormone-releasing hormone. ${ }^{[12,13]}$ According to the position statement by the South African Menopause Society, ${ }^{[14]}$ HRT can be prescribed for long-term use, and need not be routinely stopped within 5 years or by age 65 years, provided the patient has no untoward complications and continues to be monitored appropriately. However, since the prescription data analysed in this study contained no clinical indicators, it was not possible to determine whether medicines were prescribed without appropriate indications or whether existing clinical conditions may have provided reasons for, or against, the choices exercised.

The longevity of older adults is associated with musculoskeletal disorders that include osteoarthritis, rheumatoid arthritis (RA) and 
Table 3. Prevalence of potentially inappropriate drug items identified in the study

\begin{tabular}{|c|c|c|c|c|c|}
\hline Potentially inappropriate drug item & $\begin{array}{l}\text { Total study } \\
\text { population } \\
(N)\end{array}$ & $\begin{array}{l}\text { Female, } \\
n(\%)\end{array}$ & $\begin{array}{l}\text { Male, } \\
n(\%)\end{array}$ & $p$-value & Effect size $^{\star}$ \\
\hline Alprazolam & 29896 & $21523(72.0)$ & $8373(28.0)$ & $<0.001$ & 0.03 \\
\hline Amiodarone & 17433 & $7579(43.5)$ & 9854 (56.5) & $<0.001$ & 0.09 \\
\hline Amitriptyline and combinations thereof & 36509 & $27039(74.1)$ & $9470(25.9)$ & $<0.001$ & 0.04 \\
\hline Aripiprazole & 208 & $132(63.5)$ & $76(36.5)$ & 0.424 & 0.00 \\
\hline Aspirin and combinations thereof & 5447 & $2818(51.7)$ & $2629(48.3)$ & $<0.001$ & 0.03 \\
\hline Belladonna & 2 & $2(100.0)$ & - & 0.311 & $0.55^{\dagger}$ \\
\hline Brompheniramine & 21 & $11(52.4)$ & $10(47.6)$ & 0.185 & 0.00 \\
\hline Chlordiazepoxide and combinations thereof & 3926 & $2957(75.3)$ & $969(24.7)$ & $<0.001$ & 0.02 \\
\hline Chlorpheniramine & 12668 & $7369(58.2)$ & $5299(41.8)$ & $<0.001$ & 0.03 \\
\hline Chlorpromazine & 365 & $166(45.5)$ & $199(54.5)$ & $<0.001$ & 0.01 \\
\hline Clemastine & 1 & - & $1(100.0)$ & 0.163 & $0.34^{\dagger}$ \\
\hline Clomipramine & 496 & $367(74.0)$ & $129(26.0)$ & $<0.001$ & 0.01 \\
\hline Clonazepam & 5372 & $3663(68.2)$ & $1709(31.8)$ & 0.001 & 0.00 \\
\hline Clonidine & 70 & $70(100.0)$ & - & $<0.001$ & 0.01 \\
\hline Clozapine & 297 & $203(68.4)$ & $94(31.6)$ & 0.409 & 0.00 \\
\hline Cyprohepatadine & 289 & $168(58.1)$ & $121(41.9)$ & 0.004 & 0.00 \\
\hline Dexchlorpheniramine & 5605 & $3444(61.5)$ & $2161(38.5)$ & $<0.001$ & 0.01 \\
\hline Diazepam & 4395 & $2778(63.2)$ & $1617(36.8)$ & $<0.001$ & 0.01 \\
\hline Diclofenac & 36062 & $19546(54.2)$ & $16516(45.8)$ & $<0.001$ & 0.07 \\
\hline Dicyclomine and combinations thereof & 880 & $536(60.9)$ & $344(39.1)$ & 0.001 & 0.00 \\
\hline Diphenhydramine and combinations thereof & 11171 & $6177(55.3)$ & $4994(44.7)$ & $<0.001$ & 0.03 \\
\hline Digoxin & 11761 & $5567(47.3)$ & $6194(52.7)$ & $<0.001$ & 0.06 \\
\hline Dipyridamole and combinations thereof & 1866 & $891(47.8)$ & $975(52.2)$ & $<0.001$ & 0.02 \\
\hline Disopyramide & 179 & $112(62.6)$ & $67(37.4)$ & 0.321 & 0.00 \\
\hline Doxazosin & 14816 & $4235(28.6)$ & $10581(71.4)$ & $<0.001$ & 0.13 \\
\hline Doxylamine and combinations thereof & 8977 & $5746(64.0)$ & $3231(36.0)$ & $<0.001$ & 0.01 \\
\hline Ergot & 866 & $603(69.6)$ & $263(30.4)$ & 0.027 & 0.00 \\
\hline $\begin{array}{l}\text { Oestrogen and combinations thereof (oral and patch } \\
\text { formulations) }\end{array}$ & 69894 & $69845(99.9)$ & $49(0.1)$ & $<0.001$ & 0.27 \\
\hline Flecainide & 1761 & $899(51.0)$ & $862(49.0)$ & $<0.001$ & 0.02 \\
\hline Fluphenazine & 39 & $22(56.4)$ & $17(43.6)$ & 0.202 & 0.00 \\
\hline Flurazepam & 125 & $76(60.8)$ & $49(39.2)$ & 0.212 & 0.00 \\
\hline Glibenclamide & 9409 & $3724(39.6)$ & $5685(60.4)$ & $<0.001$ & 0.07 \\
\hline Haloperidol & 549 & $357(65.0)$ & $192(35.0)$ & 0.601 & 0.00 \\
\hline Hydroxyzine & 1813 & $1249(68.9)$ & $564(31.1)$ & 0.012 & 0.00 \\
\hline Hyoscine and combinations thereof & 7492 & $4832(64.5)$ & $2660(35.5)$ & 0.003 & 0.00 \\
\hline Ibuprofen and combinations thereof & 34162 & $19649(57.5)$ & $14513(42.5)$ & $<0.001$ & 0.05 \\
\hline Imipramine & 2561 & $1863(72.8)$ & $698(27.2)$ & $<0.001$ & 0.01 \\
\hline Indomethacin & 3611 & $2361(65.4)$ & $1250(34.6)$ & 0.372 & 0.00 \\
\hline Insulin (sliding scale) & 18715 & $6966(37.2)$ & $11749(62.8)$ & $<0.001$ & 0.11 \\
\hline Ketoprofen & 1464 & $922(63.0)$ & $542(37.0)$ & 0.012 & 0.00 \\
\hline Ketorolac & 2671 & $1524(57.1)$ & $1147(42.9)$ & $<0.001$ & 0.01 \\
\hline Lorazepam & 10615 & $7483(70.5)$ & $3132(29.5)$ & $<0.001$ & 0.01 \\
\hline \multirow[t]{2}{*}{ Loxapine } & 9 & $9(100.0)$ & - & 0.032 & 0.00 \\
\hline & & & & & Continued ... \\
\hline
\end{tabular}


Table 3. (continued) Prevalence of potentially inappropriate drug items identified in the study

\begin{tabular}{|c|c|c|c|c|c|}
\hline Potentially inappropriate drug item & $\begin{array}{l}\text { Total study } \\
\text { population } \\
(N)\end{array}$ & $\begin{array}{l}\text { Female, } \\
n(\%)\end{array}$ & $\begin{array}{l}\text { Male, } \\
n(\%)\end{array}$ & $p$-value & Effect size $^{*}$ \\
\hline Mefenamic acid & 1121 & $714(63.7)$ & $407(36.3)$ & 0.091 & 0.00 \\
\hline Meloxicam & 41030 & $28353(69.1)$ & $12677(30.9)$ & $<0.001$ & 0.02 \\
\hline Meperidine & 228 & $151(66.2)$ & $77(33.8)$ & 0.964 & 0.00 \\
\hline Meprobamate and combinations thereof & 27894 & $19326(69.3)$ & $8568(30.7)$ & $<0.001$ & 0.02 \\
\hline Methocarbamol & 1609 & $1080(67.1)$ & $529(32.9)$ & 0.379 & 0.00 \\
\hline Methyldopa & 3950 & $2862(72.5)$ & $1088(27.5)$ & $<0.001$ & 0.01 \\
\hline Methyltestosterone & 2 & - & $2(100.0)$ & 0.048 & 0.00 \\
\hline Metoclopramide & 7971 & $4944(62.0)$ & $3027(38.0)$ & $<0.001$ & 0.01 \\
\hline Naproxen & 1786 & $1161(65.0)$ & $625(35.0)$ & 0.335 & 0.00 \\
\hline Nifedipine & 465 & $304(65.4)$ & $161(34.6)$ & 0.747 & 0.00 \\
\hline Nitrofurantoin & 4296 & $3619(84.2)$ & $677(15.8)$ & $<0.001$ & 0.03 \\
\hline Olanzapine & 1871 & $1316(70.3)$ & $555(29.7)$ & $<0.001$ & 0.01 \\
\hline Orphenadrine and combinations thereof & 4371 & $2730(62.5)$ & $1641(37.5)$ & $<0.001$ & 0.01 \\
\hline Oxazepam & 11732 & $8527(72.7)$ & $3205(27.3)$ & $<0.001$ & 0.02 \\
\hline Paliperidone & 10 & $10(100.0)$ & - & 0.024 & 0.00 \\
\hline Pentazocine & 9 & $5(55.6)$ & $4(44.4)$ & 0.505 & 0.00 \\
\hline Phenobarbitone & 697 & $409(56.7)$ & $288(41.3)$ & $<0.001$ & 0.01 \\
\hline Pimozide & 35 & $32(91.4)$ & $3(8.6)$ & 0.002 & 0.00 \\
\hline Piroxicam & 4221 & $2586(61.3)$ & $1635(38.7)$ & $<0.001$ & 0.01 \\
\hline Prazosin & 977 & $458(46.9)$ & $519(53.1)$ & $<0.001$ & 0.02 \\
\hline Promethazine and combinations thereof & 3727 & $2324(62.4)$ & $1403(37.6)$ & $<0.001$ & 0.01 \\
\hline Propafenone & 540 & $269(49.8)$ & $271(50.2)$ & $<0.001$ & 0.01 \\
\hline Propantheline & 74 & $59(79.7)$ & $15(20.3)$ & 0.013 & 0.00 \\
\hline Quetiapine & 4977 & $3268(65.7)$ & $1709(34.3)$ & 0.527 & 0.00 \\
\hline Reserpine & 454 & $344(75.8)$ & $110(24.2)$ & $<0.001$ & 0.01 \\
\hline Risperidone & 6873 & $4378(63.7)$ & $2495(36.3)$ & $<0.001$ & 0.01 \\
\hline Sotalol & 1736 & $890(51.3)$ & $846(48.7)$ & $<0.001$ & 0.02 \\
\hline Spironolactone & 3260 & $1780(54.6)$ & $1480(45.4)$ & $<0.001$ & 0.02 \\
\hline Temazepam & 2393 & $1516(63.4)$ & $877(36.6)$ & 0.005 & 0.00 \\
\hline Terazosin & 250 & $23(9.2)$ & $227(90.8)$ & $<0.001$ & 0.03 \\
\hline Testosterone & 290 & $10(3.5)$ & $280(96.5)$ & $<0.001$ & 0.03 \\
\hline Triazolam & 1774 & $1104(62.2)$ & $670(37.8)$ & 0.001 & 0.01 \\
\hline Trifluoperazine & 168 & $136(81.0)$ & $32(19.0)$ & $<0.001$ & 0.01 \\
\hline Trimipramine & 706 & $505(71.5)$ & $201(28.5)$ & 0.002 & 0.00 \\
\hline Triprolidine and combinations thereof & 1158 & $635(54.8)$ & $523(45.2)$ & $<0.001$ & 0.01 \\
\hline Ziprasidone & 114 & $87(76.3)$ & $27(23.7)$ & 0.021 & 0.00 \\
\hline Zolpidem & 0 & - & - & & \\
\hline
\end{tabular}

osteoporosis. According to Usenbo et al., ${ }^{[15]}$ the prevalence of RA in SA for adults aged $\geq 65$ years is relatively low at $2.5 \%$ in urban settings and $0.07 \%$ in rural settings; however, that for osteoarthritis is $55.1 \%$ in urban settings and ranges from $29.5 \%$ to $82.4 \%$ in rural settings. NSAIDs are effective in controlling pain and stiffness and are often prescribed on a long-term basis for patients with RA. Meloxicam, a cyclo-oxygenase (COX) inhibitor with antipyretic, anti-inflammatory and analgesic activity, has been approved by the US Food and Drug
Administration for use in osteoarthritis. Diclofenac is a COX-2 selective inhibitor that is effective for pain relief and the prevention and alleviation of fever, and to reduce inflammation. It is also useful to treat RA, osteoarthritis and ankylosing spondylitis. Ibuprofen is useful in the treatment of RA and osteoarthritis, and may also be used to alleviate moderate pain. It is therefore not surprising that a significant proportion (19.8\%) of patients in our study population received NSAIDs, in particular meloxicam, diclofenac and ibuprofen. 
Table 4. Prevalence of the 10 most inappropriately prescribed drugs per prescriber group

\begin{tabular}{|c|c|c|c|c|c|c|c|}
\hline & $\begin{array}{l}\text { Total study } \\
\text { population } \\
(N)\end{array}$ & $\begin{array}{l}\text { GPs, } \\
n(\%)\end{array}$ & $\begin{array}{l}\text { Pharmacy, } \\
n(\%)\end{array}$ & $\begin{array}{l}\text { Specialists, } \\
n(\%)\end{array}$ & $\begin{array}{l}\text { Other, } \\
n(\%)\end{array}$ & $p$-value & Effect size $^{\star}$ \\
\hline Beers criteria item & & & & & & $<0.001$ & 0.09 \\
\hline Alprazolam & 29896 & $24073(80.5)$ & - & $4536(15.2)$ & $1287(4.3)$ & & \\
\hline Amiodarone & 17433 & $9820(56.3)$ & - & $7324(42.0)$ & $289(1.7)$ & & \\
\hline Amitriptyline and combinations thereof & 36509 & $28095(77.0)$ & - & $6793(18.6)$ & $1621(4.4)$ & & \\
\hline Diclofenac & 36062 & 22205 (61.6) & $10200(28.3)$ & $2732(7.6)$ & $925(2.6)$ & & \\
\hline Doxazosin & 14816 & $10499(70.9)$ & $1(0.0)$ & $4109(27.7)$ & 207 (1.4) & & \\
\hline $\begin{array}{l}\text { Oestrogen and combinations thereof } \\
\text { (oral and patch formulations) }\end{array}$ & 69894 & $56978(81.5)$ & $106(0.2)$ & $11368(16.3)$ & $1442(2.1)$ & & \\
\hline Ibuprofen & 34162 & $16347(47.9)$ & $12351(36.2)$ & $2312(6.8)$ & $3152(9.2)$ & & \\
\hline Insulin (sliding scale) & 18715 & $11971(64.0)$ & - & $6492(34.7)$ & $252(1.3)$ & & \\
\hline Meloxicam & 41030 & $34544(84.2)$ & - & $5765(14.1)$ & $721(1.8)$ & & \\
\hline Meprobamate and combinations thereof & 27894 & $21956(78.7)$ & $71(0.3)$ & $4447(15.9)$ & $1420(5.1)$ & & \\
\hline
\end{tabular}

Approximately 1 in 15 patients (male/female ratio 1:3) in our study population received amitriptyline or combinations thereof. A further $5 \%$ of patients received alprazolam. According to the South African Stress and Health (SASH) study ${ }^{[16]}$ the lifetime disorders most frequently encountered by South Africans are anxiety disorder (15.8\%), drug use disorders (13.3\%) and mood disturbances (9.8\%). Antidepressant medication such as amitriptyline is mainly used for the treatment of depression; however, its off-label use includes indications such as insomnia, panic disorders, alcohol dependence, pain management, and agitation in patients with dementia. ${ }^{[17]}$ Benzodiazepines are essentially used to treat acute anxiety conditions and as hypnotics, ${ }^{[12]}$ and are frequently prescribed for older persons, in particular females.

A substantial number of meprobamate-containing items were prescribed for older patients in our study population. Analgesics, in general, are one of the most frequently prescribed drug groups, particularly to women. Earlier studies conducted in SA indicated that the second and third most frequently prescribed analgesics were combinations of drugs of which meprobamate formed part of the combination. ${ }^{[18]}$ Women in these studies received analgesics containing meprobamate nearly five times more often than men, whereas in our study, women were about three times more likely to receive analgesics containing meprobamate.

Men received significantly more prescriptions than women for both sliding-scale insulin and doxazosin. Insulin is indicated for the treatment of type 1 diabetes mellitus and as a supplement in type 2 diabetes. According to the South African National Health and Nutrition Examination Survey (SANHANES-1), $\sim 19 \%$ of older patients ( $\geq 65$ years) in the country had a diagnosis of diabetes in $2012{ }^{[19]}$ At a national level, mean glycosylated haemoglobin $\left(\mathrm{HbA}_{1 \mathrm{c}}\right)$ levels increased significantly with age, reaching their highest value in the group 55 - 64 years of age. Among men in particular, the increase in mean $\mathrm{HBA}_{1 \mathrm{c}}$ values was associated with a significantly higher agerelated prevalence of impaired glucose homeostasis $\left(\mathrm{HBA}_{1 \mathrm{c}}>6.1 \%\right.$ and $<6.5 \%)$ and diabetes $\left(\mathrm{HBA}_{1 \mathrm{c}}>6.5 \%\right)$, with the highest prevalence in the groups aged $\geq 65$ years and 55 - 64 years $(19.7 \%$ and $20.9 \%$, respectively).

Benign prostatic hypertrophy (BPH) can be classified as a common urological condition that increases with age. BPH affects $40 \%$ of men in their 50s, with an increase in prevalence to $80 \%$ of men in their 70s. Medical therapy generally includes alpha-blockers such as doxazosin. ${ }^{[12]}$ It is therefore conceivable that the men in our study population received more prescriptions for doxazosin than their female counterparts.

Similar to the trend that has been observed in other studies, the potentially inappropriate items in our study were prescribed most frequently by general practitioners. It is not clear why we observed this trend; however, as noted by Chetty and Gray, ${ }^{[0]}$ the Beers criteria are limited in both sensitivity and specificity, as these criteria do not take into account the individualisation of medicine regimens by prescribers to suit individual patients' needs.

Other factors to consider when interpreting our findings include the use of only one PBM's data, so only members of the medical aid schemes administered by the selected PBM were represented in the study. The database furthermore only included claims for medicine items and not for other medical devices and interventions. Patients may also have gone in and out of eligibility, which could have led to subjects and data being missed, with subsequent under-reporting of PIPs.

\section{Conclusions}

Our study showed that PIPs according to explicit criteria were common in older patients registered on the database. In this study, women were more likely to be exposed to PIPs than their male counterparts. Although it is important to remember that the use of explicit criteria cannot substitute for clinical judgement based on the individual patient, there is a need for a prescribing measure for older adults in the SA health sector that can be used to encourage valuedriven healthcare.

Acknowledgements. The authors would like to thank Ms A Bekker for assistance with the initial data extraction from the database and Ms E Blaauw for language editing.

Compliance with ethical standards. No sources of funding were used to assist with the preparation of this manuscript. The study was conducted with the approval of the Health Research Ethics Committee of North-West University (Potchefstroom campus) (NWU-00179-14-S1) and the board 
of directors of the PBM. All procedures performed in studies involving human participants were in accordance with the ethical standards of the institutional and/or national research committee and with the 1964 Declaration of Helsinki and its later amendments or comparable ethical standards.

1. Page RL, Linnebur SA, Bryant LL, Ruscin JM. Inappropriate prescribing in the hospitalized elderly patient: Defining the problem, evaluation tools and possible solutions. Clin Interv Aging 2010;5:75-87. DOI: $10.2147 /$ CIA.S9564

2. Waite LJ. The demographic faces of the elderly. Popul Dev Rev 2004;30(Suppl.):S3-16.

3. Maio V, del Canale S, Abouzaid S. Using explicit criteria to evaluate the quality of prescribing in elderly Italian outpatients: A cohort study. J Clin Pharm Ther 2009;35(2):219-229. DOI:10.1111/j.13652710.2009.01094.x

4. Council of Medical Schemes. CMS Annual Report 2014-2015. 2014. http://www.medicalschemes. com/Publications.aspx (accessed 24 September 2015).

5. McLeod H. National Health Insurance Policy Brief 3: The impact of chronic disease on future NHI. http://www.nhisa.co.za/G_IMSA.asp (accessed 24 September 2015).

6. Malone DC, Abarca J, Hansten PD, et al. Identification of serious drug-drug interactions: Results of 6. Malone DC, Abarca J, Hansten PD, et al. Identification of serious drug-drug interactions: Results of
the partnership to prevent drug-drug interactions. J Am Pharm Assoc (Wash) 2004;44(2):142-151. the partnership to prevent drug-drug
DOI:10.1016/j.amjopharm.2005.05.001

7. Aparasu RR, Mort JR. Inappropriate prescribing for the elderly: Beers Criteria-based review. Ann Pharmacother 2000;34(3):338-346. DOI:10.1345/aph.19006

8. NPS Medicinewise. Identifying inappropriate prescribing in older people/elderly. http://www.nps. org.au/topics/ages-life-stages/for-individuals/older-people-and-medicines/for-health-professionals/ inappropriate-prescribing (accessed 26 March 2014)
9. Chetty R, Gray A. Inappropriate prescribing in an elderly population: Findings from a South African public sector survey. Int J Pharm Pract 2004;12(3):149-154. DOI:10.1211/0022357044256

10. Fick D, Semla T, Beizer J, et al. American Geriatrics Society updated Beers Criteria for potentially inappropriate medication use in older adults. J Am Geriatr Soc 2012;60(4):616-631. DOI:10.1111/
in inappropriate medication

11. Statistics South Africa. General household survey 2013. 2014. http://www.statssa.gov.za/publications/ P0318/P03182013.pdf (accessed 1 April 2016).

2. Trevor AJ, Katzung BG, Masters SB. Katzung \& Trevor's Pharmacology: Examination and Board Review. 6th ed. New York: Lange Medical Books, 2002.

13. Baum NH, Torti DC. Managing hot flashes in men being treated for prostate cancer. Geriatric 2007;62(11):18-21.

14. Guidozzi F, Alperstein A, Bagratee JS, et al. South African Menopause Society revised consensus position statement on menopausal hormone therapy. S Afr Med J 2014;104(8):537-543. DOI:10.7196/SAMJ.8423

15. Usenbo A, Kramer V, Young T, Musekiwa A. Prevalence of arthritis in Africa: A systematic review. 2015. http://www.ncbi.nlm.nih/gov/pubmed/26241756 (accessed 6 October 2015).

16. Herman AA, Stein DJ, Seedat S, et al. The South African Stress and Health (SASH) study: 12-month and lifetime prevalence of common mental disorders. S Afr Med J 2009;99(5):339-344.

17. Streator SE, Moss JT. Identification of off-label antidepressant use and costs in a network model Streator SE, Moss JT. Identification of off-label an
HMO. Drug Benefit Trends 1997; $9(9): 48-50,55-56$.

18. Truter I. An investigation into compound analgesic prescribing in South Africa, with special emphasis Truter I. An investigation into compound analgesic prescribing in South Africa, with special emphasis
on meprobamate-containing analgesics. Pharmacoepidemiol Drug Saf 1998;7(2):91-97. DOI:10.1002 on meprobamate-containing analgesics. Pharmacoepidemiol Dru
(SICI) $1099-1557(199803 / 04) 7: 2<91::$ AID-PDS331 $>3.0 . C O ; 2-K$

19. Shisana $O$, Labadarios D, Rehle T, et al. South African National Health and Nutrition Examination Survey (SANHANES-1): 2014 edition. http://www.hsrc.ac.za/en/research-data/view/6493 (accessed 1 April 2016)

Accepted 13 May 2016. 